\title{
A privacidade em tempos de pandemia e a escada de monitoramento e rastreio
}

\author{
GABRIELA CAPOBIANCO PALHARES I \\ ALESSANDRO SANTIAGO DOS SANTOS, ${ }^{I I}$ \\ EDUARDO ALTOMARE ARIENTE, "II \\ e JEFFERSON DE OLIVEIRA GOMES ${ }^{\text {IV }}$
}

\section{Introdução}

A

RECENTE pandemia da Covid-19 deu ensejo a diversos desafios globais de natureza sanitária, política, econômica e também de ordem jurídica. Para o enfrentamento da disseminação dessa moléstia, alguns governos atuaram de forma preventiva e transparente, despertando a confiança da população em suas decisões.

Coreia do Sul (Nature, 2020), Nova Zelândia (Alonso, 2020) e Singapura (Oliveira, 2020), em diferentes intensidades, vêm recorrendo a medidas de isolamento social, testes rápidos e acessíveis para detecção da doença, uso obrigatório de máscaras para evitar disseminação, além de monitoramento da locomoção das pessoas por intermédio dos aparelhos de telefonia celular.

Essa última ação suscita debate sobre as condições que legitimariam os governos de acessar informações e dados pessoais dos dispositivos móveis dos cidadãos para aferição do respeito às determinações sobre distanciamento social. Nesse sentido, em situações excepcionais de saúde pública, com foco na realidade brasileira, pretende-se verificar as condições que respaldariam juridicamente $o$ acesso pelo governo federal aos dados pessoais dos cidadãos em face do direito à privacidade.

Para atingir esse objetivo, serão analisados: i) o conteúdo jurídico do direito à privacidade; ii) a relevância do acesso a dados pessoais do governo federal perante os concessionários de serviço público de telefonia para enfrentamento da Covid-19; iii) de que forma alguns países que estão superando a pandemia monitoram suas populações e como operam suas legislações sobre privacidade; iv) quais os tipos de rastreio e monitoramento existentes, utilizados em diversos países para o combate à pandemia; v) a adequação dos direitos fundamentais envolvidos com gestão de políticas públicas de saúde pelo governo federal.

Nossas hipóteses indicam que: 1) $\mathrm{O}$ direito à privacidade é vocacionado a resguardar a vida privada dos cidadãos diante da curiosidade e intromissões in- 
devidas de outras pessoas, de pessoas jurídicas e do próprio Estado, assim como permitir a autodeterminação informativa do titular do direito; 2) neste momento de pandemia, há uma colisão entre direito à privacidade e direitos fundamentais à saúde e à vida (em seus âmbitos coletivos, sobretudo), exigindo do poder público a criação de balizas de ponderação, adequadas, proporcionais e claras para o sopesamento entre eles; 3 ) como se percebe por meio do direito comparado, essas balizas de ponderação são influenciadas por aspectos socioculturais e arcabouço jurídico pré-pandemia; 4) por fim, os critérios de proporcionalidade, adequação e necessidade também devem se correlacionar com a tecnologia escolhida pelos gestores públicos, segundo o grau de severidade do espalhamento da doença em determinada região.

A metodologia adotada para se atingir esses objetivos será a análise exploratória aplicada pelo método dedutivo e recurso aos procedimentos bibliográfico e documental. Recorrer-se-á à doutrina de conceitos jurídicos elementares; à abordagens jurisprudenciais sobre privacidade, de acordo com os nossos tribunais superiores; e, por fim, à leitura comparativa entre normas federais vigentes nacionais e exteriores sobre calamidade pública em razão da Covid-19, bem como sobre aspectos técnicos para obtenção de dados pessoais via aparelhos de telefonia celular.

\section{Direito à privacidade: delimitação dos conceitos jurídicos}

O direito à privacidade é considerado direito da personalidade associado à dignidade da pessoa humana. Dessa forma, assume especial relevância para o desenvolvimento e a proteção da personalidade (Sarlet et al., 2019, p.448).

Assim, busca-se compreender de que forma o direito à privacidade pode ser afetado pelo monitoramento de dados, informações e geolocalização adotados pelo governo federal para fins de combate à pandemia e garantia do direito à saúde. Cumpre, portanto, delimitar o conceito desse direito que será ponderado na situação em exame.

Não há consenso sobre as relações entre privacidade e intimidade, tampouco sobre o conceito preciso desses direitos. Alguns autores admitem que intimidade possui caráter mais restrito do que privacidade. Contudo, essa distinção não é tranquila de sustentar, uma vez que as diferentes esferas da vida privada possuem certa fluidez. Ainda assim, para imprimir maior coerência na linguagem adotada no presente texto, optou-se por compreender privacidade de forma abrangente, na qual o direito à vida privada (privacidade) estaria incluída (Sarlet et al., 2019, p.457). Em sentido equivalente, José Afonso da Silva entende que privacidade deve ser considerada de forma genérica, a respeito do qual direitos da esfera íntima, privada e da personalidade seriam espécies (Silva, 2001, p.209).

$\mathrm{O}$ direito à privacidade, havido num primeiro momento como direito de estar só, desfrutar de tranquilidade e de paz de espirito, remonta ao final do século XIX a partir das contribuições de Otto von Giercke, Brandeis e Warren, 
postulando o resguardo da integridade moral dos cidadãos diante da imprensa sensacionalista. Posteriormente, com De Cupis e outros autores, assumiu outros contornos, especialmente de regime jurídico de contenção, segundo o qual certas informações pessoais devem ser excluídas do conhecimento alheio. Além disso, alguns doutrinadores sustentaram o direito de os cidadãos administrarem as informações pessoais sobre si mesmos, uma faceta mais ativa desse direito (Sampaio, 1998, p.57-60).

Assim, a privacidade não teria apenas caráter negativo, de exclusão de interferências externas, mas também positivo, na medida em que o cidadão tem o direito de gerir o fluxo de informações pessoais que lhe digam respeito. Além dessas duas características, pode-se adicionar uma terceira, de controle ou limitação de acesso a certas informações pessoais em face de terceiros (ibidem, p.239-40).

Dessa forma, podemos indicar que tanto privacidade quanto intimidade são direitos fundamentais, ligados à liberdade individual, que tanto asseguram espaço do indivíduo sem interferências de terceiros para reflexão como também autonomia do indivíduo, no sentido de escolha de determinado modo de vida, assumir valores e compromissos, autodeterminação, sexualidade, consumo de substâncias que podem prejudicar a saúde, eutanásia, casamento e procriação (ibidem, p.262-3).

Em outra linha de classificação e nomenclaturas, Paulo José da Costa Junior acredita que no direito à vida privada estão abrangidos tanto o direito ao sigilo quanto o direito de não divulgação por aqueles que as obtiveram de forma lícita. O renomado penalista difere: i) a chamada esfera privada stricto sensu, acerca do do qual o titular não deseja divulgação; ii) do direito à intimidade ou esfera confidencial, do qual participam pessoas de estrita confiança do titular; e finalmente iii) a esfera do segredo, círculo mais estreito de confiança que uma pessoa pode dispor (Costa Junior, 2004, p.34).

Para uniformizar a nomenclatura adotada, seguiremos com o conceito proposto por Ingo Sarlet, entendendo o direito à privacidade de forma abrangente:

[...] direito à privacidade consiste no direito de ser deixado em paz, ou seja, na proteção de uma esfera autônoma da vida privada, na qual o indivíduo pode desenvolver a sua individualidade, inclusive e especialmente no sentido de garantia de um espaço para seu recolhimento e reflexão, sem que ele seja compelido a determinados comportamentos socialmente esperados. (Salet et al., 2019, p.458)

Como se sabe, direitos fundamentais assumem as características de universalidade, historicidade, relatividade, limitabilidade, concorrência e irrenunciabilidade (Nunes Junior; Araujo, 2012, p.136). Os direitos fundamentais, em regra, não são absolutos (salvo talvez a proscrição da tortura, do racismo e dos tribunais de exceção), uma vez que, diante da colisão entre dois direitos funda- 
mentais, é necessário esforço do intérprete para ponderar os interesses conflitantes e aplicá-los na maior proporção que a situação permitir.

Costuma-se adotar como importante baliza de defesa dos direitos fundamentais, notadamente para aferição de constitucionalidade dos atos do poder público, o princípio da proporcionalidade. Tal princípio pode ser estruturado em três níveis: i) adequação ou conformidade da medida de acordo com os fins pretendidos; ii) necessidade ou exigibilidade, que deve ser a menos restritiva possível aos direitos fundamentais; iii) proporcionalidade em sentido estrito, ou ponderação propriamente dita, no qual se analisa a correspondência entre os meios utilizados e o fim esperado (Sarlet et al., 2019, p.227).

Intimidade e privacidade, no texto constitucional brasileiro, não receberam restrições explícitas. Por decisão do seu titular, poderia haver redução voluntária, mas não de anulação ou aniquilamento deles (Sarlet et al., 2019, p.460). Dessa feita, redes sociais e aplicativos que aparentam "gratuidade" devem ser transparentes sobre a troca que se estabelece entre o acesso a determinada facilidade tecnológica e os dados pessoais fornecidos pelos seus usuários. Mais precisamente, os princípios que devem nortear a proteção de dados devem ser: 1) publicidade, no qual a existência de banco de dados deve ser de conhecimento do público; 2) exatidão, pelo qual os dados devem corresponder à realidade e serem atualizados; 3) finalidade, a partir do qual deve-se observar os objetivos indicados ao titular pelo detentor do banco de dados, em função do uso de suas informações pessoais; 4) livre acesso, que assegura ao indivíduo obter informações, cópias e controle dos seus dados pessoais perante o banco de dados; 5) segurança física e lógica, para resguardo dos dados quanto à destruição, modificação indevida, transmissão ou acesso não autorizado (Doneda, 2019, p.182).

Nessa conformidade, $\mathrm{o}$ direito à privacidade não se reveste de caráter absoluto. Por atuação legislativa, caberia em tese restrição indireta para conformação ou concretização de outro direito de relevo constitucional, como é o caso do direitos à saúde e à vida. Tais restrições devem, além de observar o núcleo essencial do direito, ser adequadas, proporcionais e necessárias para o atingimento das finalidades pretendidas (Sampaio, 1998, p.308).

\section{Pandemia e compartilhamento de dados ao IBGE}

A Medida Provisória (MP) n.954/2020, editada pela Presidência da República (Brasil, 2020e) em 17.4.2020, determinou o compartilhamento de informações sobre dados, notadamente nomes, números de telefone e dos endereços de seus consumidores, pessoas físicas ou jurídicas às empresa concessionárias de Serviço Telefônico Fixo Comutado (STFC) e do Serviço Móvel Pessoal (SMP), para fins de realização da pesquisa trimestral PNAD-Contínua, promovida pelo IBGE, com quesitos que poderiam direcionar políticas contra a Covid-19 durante o período de quarentena (Brasil, 2020c). Tal norma foi atacada por cinco Ações Diretas de Inconstitucionalidade: Conselho Federal da Ordem dos Advogados do Brasil (ADI 6387), Partido da Social Democracia Brasileira (PSDB) 
(ADI 6388), Partido Socialista Brasileiro (PSB) (ADI 6389), Partido Socialismo e Liberdade (Psol) (ADI 6390) e Partido Comunista do Brasil (PcdoB) (ADI 6393). Em razão da unidade temática, as ações foram reunidas para julgamento em conjunto com a ação de distribuição mais antiga, a ADI 6387-DF, e distribuída por sorteio para a ministra Rosa Weber (Brasil, 2020b). Considerando a pertinência desse julgado em relação ao presente artigo, consideramos relevante explorar os argumentos empregados, bem como a decisão judicial, ainda que provisória, já proferida.

A referida MP assegurava o caráter sigiloso das informações obtidas pelo Instituto $\left(\operatorname{art.} 3^{\circ}, \mathrm{I}\right)$, a vedação de compartilhamento com empresas públicas ou privadas, ou órgãos da administração direta ou indireta $\left(\operatorname{art.} 3^{\circ}, \mathfrak{S} 1^{\circ}\right)$, informações em seu site sobre a utilização das informações, bem como comprometimento de divulgação de relatório de impacto de dados pessoais $\left(\operatorname{art.} 3^{\circ}, \mathfrak{S}\right.$ $2^{\circ}$ ) e destruição dos dados após o encerramento da pandemia (art. $4^{\circ}$ ) (Brasil, 2020c).

O Conselho Federal da $\mathrm{OAB}$ impugnou a referida MP pelos seguintes motivos: i) cabimento de controle judicial sobre os requisitos constitucionais de relevância e urgência para edição de Medidas provisórias; ii) ausência de relevância e urgência para pesquisa do IBGE durante a pandemia, o que desautoriza a edição dessa MP; iii) violação do direito à autodeterminação informativa, privacidade e intimidade dos cidadãos; IV) ausência de correlação com precedente sobre caso Coaf (Recurso Extraordinário 1.055.941), de compartilhamento direto com Ministério Público, sem prévia autorização judicial, pois aquele precedente refere a procedimento formal de natureza penal, dotado de finalidade específica, destituído de controle administrativo externo e ausência de garantia de sigilo ou delimitação da responsabilidade dos agentes públicos responsáveis por assegurar o sigilo; V) violação do princípio da proporcionalidade ou proibição do excesso (adequação, necessidade, proporcionalidade) (Brasil, 2020b).

O parecer do Ministério Público Federal (MPF), de lavra do procurador-geral da República, opinou pela conformidade da MP em relação ao ordenamento jurídico brasileiro, baseado nos argumentos assim sintetizados: i) o controle judicial de requisitos constitucionais para edição de Medidas Provisórias deve ocorrer apenas em casos de flagrante desconformidade, o que não seria o caso; ii) referida Medida Provisória não atenta contra direitos fundamentais da intimidade e da vida privada; iii) tais medidas são proporcionais tendo em vista o direito à saúde; iv) necessidade de remessa de número de telefone e respectivo endereço residencial dos consumidores de serviços de telecomunicações, de pessoas naturais ou jurídicas ao IBGE, para elaboração da Pesquisa Nacional por Amostra de Domicílios Contínua (PNAD-Contínua), que totaliza 200 mil domićlios visitados a cada trimestre, diante da impossibilidade de realização de entrevistas domiciliares; v) Relevância da inclusão de quesitos na PNAD-Contínua para monitoramento sobre a Covid-19, para orientar os processos decisórios 
dos gestores públicos das diversas esferas; vi) Temporalidade da medida, caráter sigiloso e descarte dos dados ao fim da pandemia (Brasil, 2020b).

A Advocacia-Geral da União (AGU), órgão que exerce a representação jurídica da União, postulou a manutenção da Medida Provisória pelos seguintes argumentos: 1) As atribuições do IBGE estão previstas nas CF de 1988, como órgão incumbido pela União para organizar e manter os serviços oficiais de estatística, geografia, geologia e cartografia de âmbito nacional (art. 21, inciso $\mathrm{XV}$ ) e nas Leis n.5.534/1968, 5.878/1973, que determinam a obrigatoriedade de pessoas físicas e jurídicas de prestar informações, assim como o dever de manutenção de sigilo em relação às informações recebidas; 2) O Instituto possui diretrizes, comitês e políticas internas de confidencialidade sobre segurança da informação; 3) A PNAD-Contínua (PNAD), de elaboração trimestral, não pode ser adiada uma vez que consiste na principal fonte de informação que o governo federal dispõe sobre emprego, educação, renda e condições de vida da população brasileira; 4) Em razão de convênio com o Ministério da Saúde, serão inseridas perguntas aos cidadãos sobre disseminação da Covid-19, que serão úteis para a formulação de políticas públicas de enfrentamento da doença; 5) Relevância e urgência da referida Medida Provisória, cujo mérito seria indevassável por ato do Poder Judiciário, salvo caso de flagrante abuso ou excesso; 6) Inexistência de violação ao direito à privacidade, pois trata-se de compartilhamento de informações exclusivamente para fins estatísticos e não de conteúdo de comunicações telefônicas; 7) Referindo a precedentes relatados pelo ministro Dias Toffoli (ADI n.2.390, 2.386, 2.397 e 2.859), pugnou-se pela legalidade da transferência de dados entre duas entidades públicas que possuem dever de resguardar sigilo; desta forma haveria "transferência" de sigilo e não "quebra" de sigilo; 8) Proporcionalidade da medida tendo em vista os critérios de adequação, necessidade e proporcionalidade em sentido estrito; 9) Adequação da medida à Lei Geral de Proteção de Dados (mesmo que ainda não tenha entrado em vigor), a qual permite o acesso a dados pessoais aos serviços de pesquisa estatística, havido pela lei como sendo de finalidade pública (art. $5^{\circ}$, inciso XVIII) (Brasil, 2020b).

Diante desse panorama fático e jurídico, a ministra Rosa Weber, em decisão monocrática liminar, referendada pelos demais ministros do STF, decidiu: 1) A pesquisa não indicou de forma adequada objeto, finalidade e amplitude da estatística produzida, tampouco a necessidade de disponibilização dos dados nem como serão utilizados; 2) A edição da MP não mencionou, de forma explícita, que haveria relação com políticas de enfrentamento da pandemia do Covid-19; 3) A Medida Provisória não evidencia interesse público legítimo no compartilhamento de dados dos usuários, tendo em vista a necessidade, adequação e proporcionalidade da medida; 4) Ao não definir as razões e modo de uso dos dados pessoais, a MP não permite aferição dos requisitos de adequação e necessidade, vale dizer, a compatibilidade entre as finalidades pretendidas e a máxima restrição para o atingimento desses objetivo, o que destoa do direito ao devido 
processo legal; 5) A MP não menciona quais seriam os mecanismos técnicos ou administrativos voltados à segurança da informação adotados pelo IBGE, uma vez que apenas menciona delegação dessa tarefa ao presidente da Fundação IBGE, motivo pelo qual não assegura de forma adequada efetiva proteção aos direitos fundamentais em debate; 6) $O$ fato de a LGPD ainda não estar em vigor agrava o problema, pois tal norma possibilitaria responsabilizar os agentes que, de alguma forma, contribuíssem para os danos causados pelo mau uso ou vazamento de informações confidenciais; 7) Foram apresentadas 344 emendas ao texto da MP, muitas delas buscavam reduzir a coleta de dados ao mínimo necessário, obrigação de elaborar relatório de impacto de segurança da informação anteriormente à coleta e uso de dados, maior transparência na definição da finalidade e no uso dos dados compartilhados; 8) Mesmo diante da gravidade da situação de saúde pública, o seu combate não pode ocorrer mediante atropelo dos direitos fundamentais (Brasil, 2020b).

Dessa forma, podemos extrair do presente julgado, ainda em caráter provisório, que o direito à privacidade, demasiadamente valioso em contextos democráticos, precisa ser resguardado contra ingerências indevidas de pessoas físicas, jurídicas, de direito público e privado. Porém, não se trata de direito absoluto e, diante da pandemia do Covid-19, por exemplo, há necessário sopesamento com o direito à saúde pública. Assim, caso a Medida Provisória n.954/2020 atendesse a requisitos técnicos de segurança da informação, fosse mais precisa quanto à finalidade específica, anonimizasse os dados coletados, atendesse aos princípios da proporcionalidade e transparência, permitisse a auditabilidade dos procedimentos e emitisse previamente relatório de impacto, bem como instrumentos e procedimentos de responsabilização, talvez teria mais chance de lograr aprovação diante da chancela judicial da nossa Suprema Corte.

\section{Direito comparado em tempos de pandemia}

O embate teórico acerca do caso IBGE evidencia a imaturidade brasileira em relação à proteção de dados e uso de tecnologias para o implemento de políticas públicas. É certo que a controvérsia em relação a violação de privacidade e outros direitos fundamentais, neste momento de pandemia, não é privilégio de discussões em tribunais brasileiros. Diversos países vêm experimento críticas quanto às medidas adotadas, sobretudo quando há falta de transparência e falta de diálogo com a população (Wallach; Meyers, 2020).

Não obstante, há uma discrepância notável: as discussões e alterações estarem pautadas por normas postas ou consuetudinárias já vigentes.

Na Coreia do Sul, o Ato de Controle e Prevenção de Doenças Infecciosas (IDCPA) foi bastante aprimorado em 2015 devido à Crise Respiratória do Oriente Médio, quando o governo falhou em fornecer informações de maneira transparente, bem como kits de testes suficientes (Lichotti, 2020).

O IDCPA deixa bastante evidente a importância dada à coleta de informações de maneira centralizada em momentos de contágio em massa. Traçan- 
do um interessante paralelo com a solicitação dos dados na MP n.954/2020, o artigo 76-2(1) do IDCPA dispõe que informações pessoais, como nomes, números de registro de residentes, endereços e números de telefone (telefone celular, inclusive), podem ser solicitadas pelo ministro da Saúde e Bem-Estar ou pelo diretor dos Centros de Controle e Prevenção de Doenças da Coreia, se houver necessidade para a prevenção de doenças infecciosas e bloqueio da propagação da infecção (Coreia do Sul, 2016). O referido dispositivo permite ainda a exigência de fornecimento de dados de pacientes por instituições médicas, farmácias, corporações, organizações e outros indivíduos. O artigo 76-2(2), por sua vez, expande os poderes governamentais para a coleta de dados pessoais, prevendo inclusive o fornecimento, por agências responsáveis de telecomunicação, da localização de atuais e potenciais indivíduos infectados.

Os artigos 6 e 34-2 do IDCPA vão ainda mais além, ao exigir das autoridades competentes a disponibilização imediata das informações de monitoramento e rastreio, e, inclusive, o contato, de pessoas infectadas.

A leitura da lei vigente na Coreia do Sul, considerando tratar-se de uma democracia, traz à tona um novo aspecto a ser observado pelos legisladores e aplicadores do direito nacional: o regime democrático possui variações, amparadas, por sua vez, em singularidades socioculturais e experiências passadas com doenças contagiosas. Em países orientais, a centralização de poder é maior, permitindo que medidas mais radicais sejam consideradas adequadas, necessárias e proporcionais. Corrobora essa hipótese o resultado nas eleições parlamentares na Coreia do Sul, em 15 de abril, quando o partido do presidente conquistou 66\% dos votos, a maior média nos últimos 28 anos (Gallo, 2020).

Mesmo países com normas positivadas de proteção de dados semelhantes às almejadas no Brasil, o tratamento dessas informações parece ser diferente daquele proposto pelo Suprema Tribunal de Justiça brasileiro.

A fim de dar segurança aos Estados-membro da União Europeia, o Conselho Europeu de Proteção de Dados (EDPB) emitiu um comunicado, em 19 de março de 2020, sobre o processamento de dados pessoais, considerando o espalhamento da Covid-19 (Uniao Europeia, 2020).

Segundo o comunicado, o Regulamento Geral de Proteção de Dados europeu (GDPR) é uma legislação genérica e abarca também fundamentos para a criação de normas sobre dados pessoais em um momento de pandemia. A GDPR permite que autoridades de saúde pública empresas particulares relacionadas à saúde pública e empregadores ${ }^{1}$ processem dados pessoais nesse contexto, de acordo com a legislação nacional e as condições específicas da doença em cada Estado-membro.

O governo alemão, por exemplo, propôs uma emenda à "Lei de Proteção à Infecção", no intuito de permitir que o Ministério da Saúde requisitasse de pessoas com risco de serem vetores de contaminação seus dados de histórico de viagem e de pessoas com as quais se relacionaram. (Alemanha, 2020) 
$\mathrm{Na}$ Itália, o governo federal, diante do aumento vertiginoso de casos no país, publicou um decreto que contempla, entre outros assuntos, um aparato legal específico para coleta e transferência de dados pessoais relacionados à saúde. Essa permissão específica é válida tanto para autoridades públicas da área de saúde quanto para empresas que fazem parte do sistema nacional de saúde. O decreto será vigente enquanto perdurar o estado de emergência declarado nacionalmente (Itália, 2020a, p.5-6).

Esse decreto, porém, não cria novos poderes, mas explora a capacidade de utilização de poderes já determinados em lei nacional e internacional, em momentos de crise no país. No artigo 14 , referente à proteção da privacidade e dados pessoais, verifica-se a evocação dos artigos $9^{\circ}$ e $10^{\circ}$ e 23 , parágrafo 1 , letra e), da GDPR, que tratam da exceção ao direito de privacidade, bem como de dispositivos nacionais, em especial o artigo 82, capítulo V, do Decreto Legislativo de 30 de junho de 2003 , n.196, que permite a utilização de dados pessoais sem consentimento prévio de seu titular, em casos de emergência (Italia, 2020b).

Com relação à anonimização de dados pessoais em processamento de dados de telefonia, a GDPR permite sua relativização, desde que a medida seja necessária, apropriada e proporcional para a salvaguarda da segurança pública em uma democracia (art. 15). A necessidade implica, primeiramente, a existência anterior de tentativa de contenção da crise através de dados anonimizados. Caso as medidas de rastreio e monitoramento anonimizado não tenbam surtido efeito, pode-se recorrer ao afrouxamento da anonimização, por tempo limitado, enquanto perdurar a situação de emergência. Ademais, essas medidas devem estar de acordo com a Carta de Direitos Fundamentais e a Convenção Europeia para a Proteção dos Direitos Humanos e Liberdades Fundamentais. Além disso, estão sujeitas ao controle da Corte Europeia de Justiça e da Corte Europeia de Direitos Humanos.

Interessante observar o paralelo entre o comunicado do EDPB e o voto da ministra Rosa Weber, em especial porque a GDPR serviu de inspiração à LGPD brasileira, mencionada pela ministra (ainda não em vigor, mas, de alguma forma, com seus efeitos antecipada em seu voto). Primeiramente, as normas europeias e de seus Estados-membro elaboradas no contexto da Covid-19, a exemplo de Alemanha e Itália, autorizam autoridades públicas e até mesmo empregadores a coletarem dados pessoais de sujeitos a eles ligados, no intuito de proteger a segurança e saúde públicas coletivas. Nesse sentido, o controle seria realizado de maneira negativa, posteriormente ao ato, tanto por intermédio das autoridades responsáveis pela proteção de dados quanto pelo sistema jurídico respectivo. No caso do voto da ministra Rosa Weber, membro do Judiciário brasileiro, não apenas houve a proibição de coleta dos dados pelo IBGE, como a exigência de apresentação de estudo de impacto da medida proposta na MP 954/2020, antes da referida coleta. Essa discrepância poderia sugerir uma desconfiança mais acentuada em relação aos dirigentes políticos brasileiros e suas técnicas de atuação em momentos de crise. 
Além disso, o Comunicado do EDPB permite o tratamento do conceito da anonimização como princípio e não como regra (Amorim, 2005, p.1258). Em outras palavras, tratar um dado de maneira anônima ou não depende da gravidade da situação à qual se relaciona e da necessidade de utilização de tecnologia de maior ou menor precisão para a proteção do interesse público. A gradação, analogamente interpretada como "degraus" de tecnologia disponíveis atualmente para monitoramento e rastreio de informações, será abordada no próximo item, e talvez forneça pistas sobre uma possível conciliação entre privacidade e o direito coletivo à saúde.

\section{A Escada de Monitoramento e Rastreio}

Como a Covid-19 espalha-se apenas onde os humanos se encontram e, como no mundo moderno, 5,1 bilhões de pessoas ( $67 \%$ da população mundial) usam algum tipo de aparelho de telefone celular (no Brasil 97\% utilizam), o monitoramento e o controle de deslocamento de populações têm sido amplamente utilizados pelos países, tanto para contenção do vírus quanto para os processos de retorno às atividades (Bahia; Suardi, 2019).

Por esse motivo, a utilização de dados fornecidos por aparelhos móveis de telecomunicação mostra-se tão atraente para o combate da pandemia. Contudo, existem métodos distintos de captação desses dados, mais ou menos precisos, que, combinados com uma legislação adequada e transparência de informações à população, podem consolidar uma eficiente política pública ante ao espalhamento de doenças altamente contagiosas. A essa combinação de utilização gradual de tecnologias de maior precisão com normas claras que estabeleçam os critérios de avanço em relação à privacidade dos indivíduos dar-se-á o nome de Escada de Monitoramento e Rastreio.

Segundo o Escada de Monitoramento e Rastreio, cada degrau ou andar da Escada oferece um nível de monitoramento distinto. Quanto mais alto ou elevado, maior o nível de precisão dos dados e, pois, de sopesamento da privacidade. Além disso, a Escada é móvel e a velocidade de sua escalada, variável. Trazendo para o plano prático, caso a gravidade e a aceleração da contaminação aumentasse em determinado sítio, os gestores públicos, amparados por legislação adequada, poderiam, com base na Escada, solicitar a utilização de medidas excepcionais de coleta de dados individualizados, anonimizados ou não (a depender da situação), de maneira ágil e cirúrgica.

A Escada traz cinco variações ou graus de intervenção na privacidade mediante o monitoramento e rastreio.

O primeiro é a identificação de padrões de mobilidade de grupos de pessoas. Para essa identificação, é necessário o monitoramento da mobilidade do grupo de pessoas anonimizadas, a fim de se calcular índices de isolamento por municípios ou regiões. Esse estágio inicial de monitoramento visa avaliar probabilidades de crescimento da disseminação, identificando regiões com maiores probabilidades de contágio. 
O segundo é a identificação de regiões de aglomeração de grupo de pessoas. Seu escopo é a monitoração de regiões que possuem diferentes níveis de aglomeração, para reduzi-las ou eliminá-las, em especial nas regiões mais críticas.

O terceiro corresponde a identificação de mapas de origem de destino, ou seja, verificar o percurso da população. Neste grau de precisão, pode-se identificar, por exemplo, se indivíduos de zonas com maior índice de contaminação estão se deslocando para outras regiões - o que aumentaria a probabilidade de alastramento da doença.

O penúltimo degrau permite a identificação de características econômicas e individuais. Nesse diapasão, a coleta das informações se direciona à identificação das empresas-destino dos indivíduos. Nesse grau, dados sobre sexo, faixa etária e classe social já são identificados.

Por fim, o último e mais avançado nível de precisão de dados, com o rastreio individual de pessoas, de maneira não anonimizada, com foco em indivíduos infectados, permitindo, inclusive, sanções àqueles que não obedecerem o distanciamento social em prol da saúde coletiva.

Nos cinco níveis, as tecnologias envolvidas abrangem a infraestrutura celular (antenas) e aplicativos com Global Positioning System (GPS).

O modelo de cruzamento de dados de antenas tem a vantagem de monitorar $100 \%$ da população cadastrada com equipamentos móveis, sem necessitar de intervenção do usuário. Não obstante, a precisão ocorre em razão da quantidade de antenas e de alterações geográficas. Já a técnica por aplicativos apenas funciona em um smartphone que possua GPS, o que pode implicar uma amostra menor da população. Seu benefício, porém, consiste no possível cruzamento e análise de informações inseridas pelo usuário, de acordo com protocolos estratégicos a serem permitidos (Barros, 2020). ${ }^{2}$

No nível 5 (cinco) da Escada de Monitoramento e Rastreio, esses mecanismos podem evoluir para estabelecer um processo de rastreamento de contatos (World Health Organization, 2020, p.1-7), permitindo mapear pontos de possíveis contágios. Como já restou demonstrado, a Coreia do Sul estabeleceu esse nível de rastreamento em lei já em 2015, nos artigos 6 e 34-2 do IDCPA, mencionados acima (Ferretti et al., 2020).

Evidentemente, como também já disposto, a sistemática de uso deve estar claramente definida, positivada no ordenamento jurídico vigente, evitando, assim, controvérsias anteriores à aplicação da tecnologia e o retardo no combate à disseminação de vírus.

\section{Conclusão}

O presente estudo buscou, mediante união entre direito comparado e ciências exatas da computação, identificar as possibilidades tecnológicas de monitoramento e rastreio de dados que podem ser aplicadas neste momento de crise, sem que se olvide das limitações impostas pelo direito fundamental à privacidade. Essas restrições oriundas da privacidade foram incorporadas à teoria da 
Escada de Monitoramento e Rastreamento aqui proposta, sendo, pois, elemento parte e não alheio à solução.

A Escada de Monitoramento e Rastreio foi elaborada de acordo com o contexto jurídico e social brasileiro, devido a dois fatores. Primeiramente, os materiais analisados demonstraram que as estratégias de contenção da pandemia precisam respeitar idiossincrasias de cada sociedade. Mesmo dentro de regimes democráticos, há uma variação bastante significante entre as possibilidades de sopesamento da privacidade para o enfrentamento de uma doença. Em especial, populações localizadas em países orientais tendem a concordar com medidas mais radicais de monitoramento e rastreio, em especial mas, não apenas, porque vivenciaram crises passadas, relacionadas à doenças infecciosas semelhantes. A legislação da Coreia do Sul mostrou-se paradigmática, ao evidenciar que o poder de controle de dados pessoais não implica perdas no regime democrático desde que haja consentimento e aprovação da população bem como, e talvez sobretudo, transparência constante das autoridades políticas em relação à coleta, uso e transferência desses dados.

Nesse diapasão, os valores de necessidade, proporcionalidade e adequação para adoção de medidas mais ou menos restritivas em relação à privacidade tornam-se relativos, exigindo uma proposta de sua parametrização tanto no Direito nacional quanto por meio de estratégias bem definidas e transparentes de atuação do Estado. Em outras palavras, a identificação de uma medida de cerceamento de liberdade e privacidade como muito ou pouco rigorosa não é exata. Ela demanda a criação de propostas claras sobre quais intervenções tecnológicas para a coleta de dados seriam adequadas, proporcionais e necessárias em relação aos distintos graus de gravidade do contágio do vírus pela população.

A Escada de Monitoramento e Rastreio aqui proposta visa atingir esse escopo. Trata-se de um método simples e eficaz de avaliação facilmente demonstrável para a sociedade que possui como motor de sua execução de cada um dos cinco níveis de monitoramento e rastreio a autorização expressa em norma vigente.

Com isso, não se espera esgotar a polêmica sobre o sopesamento de direitos fundamentais em momentos de crises de saúde como a que se hoje vivencia. Outrossim, há, nessas poucas páginas de bastante lavoro e reflexão, a esperança de trazer positivas e ainda pouco exploradas perspectivas de solução.

Agradecimentos - Ao professor José da Rocha Carvalheiro, pela indicação ao convite para este artigo. Ao Observatório de Inovação e Competitividade do Instituto de Estudos Avançados da USP, pelas conexões entre atores no ambiente de inovação, tão essencial ao desenvolvimento intelectual e econômico em uma sociedade. Ao Instituto de Pesquisas Tecnológicas, com seu papel indispensável no auxílio aos setores público e privado neste momento de crise. Às nossas famílias e amigos, por todo o suporte e carinho. 
Notas

1 Segundo o comunicado, o processamento de dados por parte do empregador pode se relacionar às suas obrigações legais de segurança e higiene no ambiente de trabalho ou em relação ao interesse público.

2 Existem ainda outras tecnologias, como Bluetooth, que permitem comunicação sem fio entre celulares a curta distância, e essa é usada por grandes empresas, como Google e Apple para criar mecanismos de busca para saber se o usuário esteve próximo ou não de pessoas contaminadas.

\section{Referências}

ALEMANHA. FH GEBT Bevölkerungsschutz, Formulierungshilfe für die Koalitionsfraktionen für einen aus der Mitte des Deutschen Bundestages einzubringenden. Disponível em: <https://www.bundesgesundheitsministerium.de/fileadmin/Dateien/3_Downloads/Gesetze_und_Verordnungen/GuV/S/Entwurf_Gesetz_zum_ Schutz_der_Bevoelkerung_bei_einer_epidemischen_Lage_von_nationaler_Tragweite. pdf>. Acesso em: 21 maio 2020.

ALONSO, L. Empática e eficaz, Jacinda conduz Nova Zelândia a fase mais branda de restrições. Disponível em: <https://wwwl.folha.uol.com.br/mundo/2020/04/ empatica-e-eficaz-jacinda-conduz-nova-zelandia-a-fase-mais-branda-de-restricoes. shtml?aff_source=56d95533a8284936a374e3a6da3d7996>. Acesso em: 27 abr. 2020 .

AMORIM, L. B. A distinção entre regras e princípios segundo Robert Alexy. Esboço e Críticas, Brasília, v.42, n.165, jan./mar. 2005. Disponível em: <https://wwwl2.senado.leg.br/ril/edicoes/42/165/ril_v42_nl65_pl23.pdf>. Acesso em: 18 maio 2020.

BAHIA, K.; SUARDI, S. The State of Mobile Internet Connectivity 2019. GSM Association. UK, 2019. p.60. Disponível em: <https://www.gsma.com/mobilefordevelo$\mathrm{pment} / \mathrm{resources} /$ the-state-of-mobile-internet-connectivity-report-2019>. Acesso em: 24 maio 2020.

BARroS, R. Pesquisa Fapesp. Pademia - De olho na população. Notícias em 13 de maio, 2020. Disponivel em: <https://revistapesquisa.fapesp.br/2020/05/13/de-olho-na-populacao/>. Acesso em: 25 maio 2020.

BBC. Coronavirus privacy: Are South Korea's alerts too revealing? Disponível em: <https://www.bbc.com/news/world-asia-51733145>. Acesso em: 5 mar. 2020.

BRASIL. Supremo Tribunal Federal. Medida Cautelar em Ação Direta de Inconstitucionalidade n.6.387-DF. Rel. Min. Rosa Weber. Conselho Federal da Ordem dos Advogados do Brasil - CFOAB x Presidência da República. J. 24 abr. 2020a.

Supremo Tribunal Federal. Ministra Rosa Weber solicita informações ao IBGE e à Anatel sobre compartilhamento de dados. Disponível em: <http://portal.stf. jus.br/noticias/verNoticiaDetalhe.asp?idConteudo=441973\&ori=1>. Acesso em: 21 maio 2020 b.

Lei n.13.979/2020. Dispõe sobre as medidas para enfrentamento da emergência de saúde pública de importância internacional decorrente do coronavírus responsável pelo surto de 2019. Disponível em: <http://www.planalto.gov.br/ccivil_03/_ ato2019-2022/2020/lei/L13979.htm>. Acesso em: 17 maio 2020c. 
BRASIL. Decreto Legislativo 06, de 2020. Disponível em: <http://www.planalto.gov. br/ccivil_03/portaria/DLG6-2020.htm>. Acesso em: 18 maio 2020d.

Medida provisória 954/2020. Dispõe sobre o compartilhamento de dados por empresas de telecomunicações prestadoras de Serviço Telefônico Fixo Comutado e de Serviço Móvel Pessoal com a Fundação Instituto Brasileiro de Geografia e Estatística, para fins de suporte à produção estatística oficial durante a situação de emergência de saúde pública de importância internacional decorrente do coronavírus (Covid-19), de que trata a Lei n.13.979, de 6 de fevereiro de 2020. Disponível em: <http://planalto.gov.br/CCIVIL_03/_Ato2019-2022/2020/Mpv/mpv954.htm>. Acesso em: 21 maio 2020e.

. Supremo Tribunal Federal. MC - ADI 6387/DF, Rel. Min. Rosa Weber. CFOAB x Presidente da República. Disponível em: <http://www.stf.jus.br/arquivo/ cms/noticiaNoticiaStf/anexo/ADI6387MC.pdf>. Acesso em: 21 maio 2020.

COREIA DO SUL. Ato de Controle e Prevenção de Doenças Infecciosas, Lei n.14316, 2. dez, 2016. Emenda Parcial, Data de execução 3 jun. 2017. Disponível em: <http:// www.law.go.kr/LSW/lsInfoP.do?lsiSeq=188080\&chrClsCd=010203\&urlMode=engL sInfoR\&viewCls=engLsInfoR\#0000>. Acesso em: 27 maio 2020.

COSTA JUNIOR, P. J. O direito de estar só: a tutela penal do direito à intimidade. São Paulo: Siciliano Jurídico, 2004.

DE MONTJOYE, Y. et al. On the privacy-conscientious use of mobile phone data. Sci Data, v.5, 180286, 2018. Disponível em: <https://doi.org/10.1038/sdata.2018.286>. Acesso em: 20 maio 2020.

DE NEGRI, F. et al. Ciência e Tecnologia frente à pandemia. Disponível em: <https:// www.ipea.gov.br/cts/pt/central-de-conteudo/artigos/artigos/182-corona>. Acesso em: 17 maio 2020.

DONEDA, D. Da privacidade à proteção de dados pessoais. São Paulo: RT, 2019.

DU, L.; HUANG, G. Bloomberg. Did Japan Just Beat the Virus Without Lockdowns or Mass Testing? Newn on 22-5-2020, 2020. Disponivel em: <https://www.bloomberg. com/news/articles/2020-05-22/did-japan-just-beat-the-virus-without-lockdowns-or-mass-testing?utm_content=business\&cmpid=socialflow-facebook-business\&utm_ source=facebook\&utm_campaign=socialflow-organic\&utm_medium=social $>$. Acesso em: 26 maio 2020.

FERRETTI, L. et al. Quantifying SARS-CoV-2 transmission suggests epidemic control with digital contact tracing. Science, v.368, n.641, p.8, 8 maio 2020.

GALLO, W. South Korea Balances Privacy, Public Health in Virus Fight. Disponível em: <https://www.voanews.com/east-asia-pacific/south-korea-balances-privacy-public-health-virus-fight>. Acesso em: 27 maio 2020.

ITALIA. Gazzetta Ufficiale della Repubblica Italiana, edizione straordinaria, anno ${ }^{\circ}$ 161, numero 62, artigo 14, p.5-6. Disponível em: <https://www.gazzettaufficiale.it/ $\mathrm{eli} / \mathrm{gu} / 2020 / 03 / 09 / 62 / \mathrm{sg} / \mathrm{pdf}>$. Acesso em: 21 maio $2020 \mathrm{a}$.

. Decreto Legislativo 30 giugno 2003, n.196, Codice in Materia di Protezione dei Dati Personali. Disponível em: <https://www.camera.it/parlam/leggi/ deleghe/03196dll.htm>. Acesso em: 25 maio 2020b. 
LICHOTTI, C. Pouco teste para muito vírus, Ministério da Saúde diz que fez 46 mil testes até agora, mas admite que faltam kits. Disponível em: $<$ https://piaui.folha.uol. com.br/pouco-teste-para-muito-virus/>. Acesso em: 24 maio 2020.

LOH, T. Bloomberg. Who's Succeeding Against the Coronavirus and Why. News 22-5-2020, 2020. Disponivel em: <https://www.bloomberg.com/news/articles/2020-05-22/who-s-succeeding-against-the-coronavirus-and-why-quicktake>. Acesso em: 26 maio 2020.

NATURE. South Korea is reporting intimate details of COVID-19 cases: has it helped? Disponível em: <https://www.nature.com/articles/d41586-020-00740-y>. Acesso em: 15 maio 2020.

NUNES JUNIOR, V. S.; ARAUJO, L. A. D. Curso de Direito Constitucional. São Paulo: Verbatim, 2012.

OLIVEIRA, F. Ir à rua em Singapura na pandemia traz tranquilidade e tristeza, conta brasileiro. Disponível em <https://wwwl.folha.uol.com.br/mundo/2020/05/ir-a-rua-em-singapura-na-pandemia-traz-tranquilidade-e-tristeza-conta-brasileiro.shtml>. Acesso em: 16 maio 2020.

SAMPAIO, J. A. L. Direito à intimidade e à vida privada. Belo Horizonte: Del Rey, 1998.

SARLET, I.; MARINONI, L. G.; MITIDIERO, D. Curso de Direito Constitucional. 8.ed. São Paulo: Saraiva, 2019.

SILVA, J. A. da. Curso de Direito Constitucional Positivo. São Paulo: Malheiros, 2001.

UNIÃO EUROPEIA. Statement on the processing of personal data in the context of the Covid-19outbreak. Adopted on 19 March 2020. Disponível em: <https:// www.ldi.nrw.de/mainmenu_Aktuelles/Inhalt/Corona-Pandemie-und-Datenschutz/ EDPB-Statement.pdf>. Acesso em: 21 maio 2020.

WALLACH, P. A.; MEYERS, J. The federal government's coronavirus response - Public health timeline. Disponível em: <https://www.brookings.edu/research/the-federal-governments-coronavirus-actions-and-failures-timeline-and-themes/>. Acesso em: 26 maio 2020.

WORLD HEALTH ORGANIZATION. Contact tracing in the context of Covid-19. Disponível em: https://www.who.int/publications/i/item/contact-tracing-in-the-context-of-covid-19. Acesso em: 20 mai. 2020.

ZANON, J. C. Direito à proteção de dados pessoais. São Paulo: RT, 2013.

RESUMO - O direito fundamental à privacidade passou, nesses últimos meses, a entrar em um embate até então não dimensionado pelo ordenamento jurídico brasileiro em relação ao direito fundamental à saúde. Com a pandemia instaurada pela Covid-19, gestores públicos viram-se obrigados a buscar de maneira efetiva e ágil a resolução da crise no setor público de saúde. A tecnologia de monitoramento e rastreio de dados pessoais demonstrou ser a solução mais eficaz para se atingir esse escopo. O presente artigo visa, pelo estudo do Direito comparado e técnicas de monitoramento e rastreio existentes, propor um método de ação que auxilie o poder público a conter a disseminação da Covid-19, sem olvidar a relevância atrelada ao direito à privacidade. 
PALAVRAS-CHAVE: Pandemia, Direitos fundamentais, Saúde, Privacidade, Proteção de dados, Monitoramento, Rastreio, Covid-19, Legislação, Democracia, Tecnologia.

ABSTRACT - Over the past few months, the fundamental right to privacy has started to clash with the fundamental right to health in manners never previously contemplated in Brazilian legal system. The covid-19 pandemic forced public administrators to seek effective and nimble solutions to the public health crisis. The technology for monitoring and tracking personal data has proven to be the most effective solution to achieve this goal. This article, through the study of comparative law and existing monitoring and tracking techniques, aims to propose a method of action that helps government officials to contain the spread of covid-19, without forgetting the relevance of the right to privacy.

KErWORDS: Pandemic, Fundamental rights, Health, Privacy, Data protection, Monitoring, Tracking, Covid-19, Legislation, Democracy, Technology.

Gabriela Capobianco Palhares é coordenadora do Núcleo Jurídico do Observatório de Inovação e Competitividade da Universidade de São Paulo (USP), conselheira do Fórum de Empreendedores de São Paulo; advogada graduada na USP, voltada ao ramo de startups e inovação. @ - gabrielapalhares.adv@gmail.com /

https://orcid.org/0000-0002-6034-8653.

Alessandro Santiago dos Santos é doutor em Engenharia de Transportes e mestre em Computação pela Universidade de São Paulo (USP); pesquisador e gerente no Instituto de Pesquisas Tecnoógicas (IPT); coordenador do Sistema de Informações e Monitoramento Inteligente do Comitê de Crise do Coronavírus em São Paulo.

@ - alesan@ipt.br / http://orcid.org/0000-0003-0037-980X.

Eduardo Altomare Ariente é doutor e mestre em Direito pela Universidade de São Paulo; professor de Direito do Consumidor, Direito Constitucional, Direito da Inovação e coordenador do Núcleo de Inovação Tecnológica (NIT) da Universidade Presbiteriana Mackenzie. @-eduariente@gmail.com / https://orcid.org/0000-0001-9115-1899.

Jefferson de Oliveira Gomes é diretor-presidente do Instituto de Pesquisas Tecnológicas (IPT), professor da Divisão de Engenharia Aeronáutica-Mecânica do Instituto Tecnológico de Aeronáutica (ITA), bolsista de produtividade em pesquisa pelo CNPq.

@ - jefferson@ipt.br / https://orcid.org/0000-0002-6004-799X.

Recebido em 31.5.2020 e aceito em 24.6.2020.

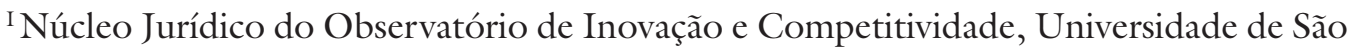
Paulo, São Paulo, Brasil.

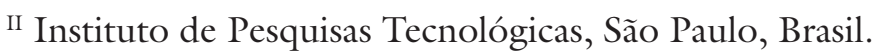

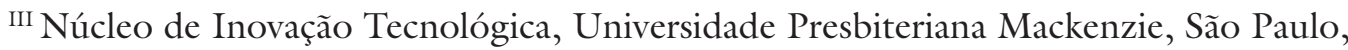
Brasil.

IV Divisão de Engenharia Aeronáutica-Mecânica, Instituto Tecnológico de Aeronáutica, São José dos Campos, São Paulo, Brasil. 